Vol. 4, Issue 1, November 2021

\title{
E-Corps' Implementation of Environmental Sustainability-Focused Service-Learning: Conditions Supporting the Establishment of an Epistemic Community
}

\author{
Rebecca Campbell-Montalvo', Todd Campbell', Byung-Yeol Park', Chester Arnold ${ }^{4}$, John C. Volin ${ }^{5}$, \\ Maria Chrysochoou ${ }^{2}$, and Peter C. Diplock ${ }^{3}$ \\ ${ }^{1}$ Department of Curriculum and Instruction, ${ }^{2}$ Department of Civil and Environmental Engineering, and ${ }^{3}$ Center for Excellence in Teaching and Learning, University of \\ Connecticut, Storrs, CT; ${ }^{4}$ Center for Land Use Education and Research, University of Connecticut, Haddam, CT; and ${ }^{5}$ School of Forest Resources and Office of the \\ Executive Vice President for Academic Affairs and Provost, University of Maine, Orono, ME
}

Keywords: Design-based implementation research, sustainability, environmental education, epistemic community, university-community partnership

Publication Date: November 3, 2021

DOI: https://doi.org/10.15695/jstem/v4i1.12

\begin{abstract}
Background: Environmental sustainability-focused service-learning programs can aid communities in addressing environmental problems and provide students with hands-on training. Understanding the implementation of such programs can inform research and application. Purpose: We investigate the implementation of an environmental sustainability-focused service-learning program (E-Corps) at a large New England public university. Our inquiry sought to better understand epistemic communities by addressing the research question: What conditions, including contextual factors and resources (i.e., funding, university context) and people (i.e., faculty, their orientation to teaching, how they work together), supported the establishment of an epistemic community in the implementation of E-Corps? Methodology/Approach: We employ frameworks of 1) Design Based Implementation Research (DBIR), which considers problems from multiple stakeholders' perspectives, collaborative design, pedagogical theory and knowledge, and capacity for sustaining change, and 2) epistemic communities - the stakeholders recursively generating, using, and refining pedagogical knowledge. We thematically analyzed interviews with students $(n=7)$, two rounds of interviews with faculty $(n=7)$, and participant observations of four E-Corps team meetings $(n=13)$. Findings/Conclusions: Findings show that epistemic community within E-Corps' implementation was supported by 1) an existing context of resources within the university, and 2) a robust university-partnership prioritizing community benefits with aligned instructor approaches. Our work informs both research on DBIR and epistemic communities as well as the practical implementation of university-community environmental partnerships.
\end{abstract}

\section{INTRODUCTION}

Similar to how other university-community partnerships seek to offer students hands-on training and help communities address social problems (e.g., Begun et al., 2010; Maurana and Goldberg, 1996), the Environment Corps (E-Corps) service-learning program seeks to address the lack of STEM-related skills in New England communities in order to help those communities better prepare for and weather current and coming environmental concerns (Hyde and Barrett, 2017). This is accomplished in the E-Corps service-learning program through three similarly designed courses each focused on a unique environmental concern: climate change, brownfields, and stormwater management. More specifically related to each of the three courses, a focus on climate change supports communities with much-needed assistance for adapting to a changing climate (e.g., designing

strategies for addressing sea level rise in coastal communities), a focus on brownfields supports the redevelopment of abandoned or underutilized sites where the reuse of property has not occurred due to contamination, and a focus on stormwater management supports innovative management practices for urbanized areas most vulnerable to stormwater impacts (e.g., flooding, increased pollution). However, local communities are struggling to marshal resources to fulfill their responsibilities to their residents and state and federal governments in connection to these current and coming environmental concerns (Hyde and Barrett, 2017). In these contexts, the need for STEM-related skills and competencies is critical for environmental tasks such as climate resilience, brownfield redevelopment, and stormwater management locally, across the country, and in locations around the world. 
To address such needs, E-Corps combines classroom instruction, service-learning, and extension outreach to create a method of engagement between the university community (students, faculty, etc.) and local communities (Arnold et al., 2021).

Scholars differ on how they define service-learning (c.f. Salam et al., 2019), with the following priorities and benefits being common:

[Service-learning is a] course-based, credit-bearing educational experience in which students (a) participate in an organized service-activity that meets identified community needs and (b) reflect on the service-activity in such a way as to gain further understanding of course content, a broader appreciation of the discipline, and an enhanced sense of civic responsibility. (Bringle and Hatcher, 1995, $p$. 112)

Service-learning can help students, faculty, and stakeholders apply knowledge from courses to real-world scenarios of consequence (Meyer et al., 2016) and develop a deeper and more connected understanding of course content (Dienhart et al., 2016). Service-learning also helps students experience reciprocity between the university campus and local communities (Olberding and Hacker, 2016), as well as develop increased facility with problem solving (Geller et al., 2016). However, Volchok (2017) notes an underlying tension between helping students achieve learning outcomes and ensuring that service-learning partners also benefit.

With its real-world and environmental focus, the implementation of environmentally-related service-learning programs has unique needs in comparison to the implementation of other types of service-learning programs. Generally, previous work has called for a needed emphasis on research about service-learning to improve it, as well as detailed the steps general service-learning programs may take to get off the ground (Bringle and Hatcher, 2000). Specifically, Bringle and Hatcher (2000) used a questionnaire with 179 participants attending conferences on service-learning from a range of university types and found that deliberate institutional planning, the development of campus infrastructure, and having a centralized office out of which service-learning programming is run were important factors in launching service-learning programming. These findings offer a starting point to consider how environmentally-focused service-learning might be implemented. However, because these conclusions are not tied to a specific type of service-learning program, how much they generalize to environmentally-focused service-learning remains to be seen. Work specifically on environmentally-focused service-learning tends to examine such facets as student learning or behavioral outcomes (Eflin and Sheaffer, 2006; England and Marcinkowski, 2007;
Helicke, 2014; Hughes and Estes, 2005) or environmental outcomes (Yoshino, 2005), rather than implementation.

In addition, how the needs of environmentally-related service-learning programs are met must also be identified to inform the intersecting bodies of literature informing this topic. Design Based Implementation Research (DBIR) offers a promising frame of analysis in this arena, since it is a type of program implementation that seeks to create educational policies and programs that work, can be scaled, and are sustainable (Fishman et al., 2013). Glazer and Peurach's epistemic community theory (2015) also offers a lens to understand how people work together to implement service-learning programming, as epistemic communities are defined as people, teams, and units that are coordinated, aligned, and work together to achieve a goal.

Using DBIR and epistemic community theory, we draw on interviews with E-Corps students and faculty and observations with instructors. We address the following research question: What conditions, including contextual factors and resources (i.e., funding, university context) and people (i.e., faculty, their orientation to teaching, and how they work together) supported the establishment of an epistemic community in the implementation of E-Corps? In investigating this research question we aim to: 1) generate transferrable knowledge for other implementations of environmentally-related service-learning programming that seek to establish epistemic communities as foundations for such programming, and 2) generate theory for researchers, especially those drawing on DBIR and epistemic community frameworks to ground their work. In this current research, we go beyond the existing literature by identifying the factors affecting the implementation of environmentally-focused service-learning, a needed contribution to expand environmentally-related service-learning programs.

\section{Theoretical Perspective: Design Based Implementation} Research and the Epistemic Community. A DBIR approach was articulated by the E-Corps team in their funding proposal to guide their efforts in which they intentionally sought to negotiate and coordinate the actions of various stakeholders within a complex institutional ecology (Penuel et al., 2011). The stakeholders included project members within (e.g., professors, administrators) and beyond (e.g., community partners) the university. Fishman et al. (2013) define the four main tenets of DBIR:

1. A focus on persistent problems of practice from multiple stakeholders' perspectives;

2. A commitment to iterative, collaborative design;

3. A concern with developing theory and knowledge related to both classroom learning and implementation through systematic inquiry; and 
4. A concern with developing capacity for sustaining change in systems (Fishman et al., 2013, p. 136).

Given E-Corps' articulated DBIR orientation, in this study, we focused on understanding the resources, including contextual factors and people, that supported the implementation of E-Corps specifically from the perspective of how university actors involved in the implementation of E-Corps program may have mobilized DBIR.

At the same time, we used epistemic community theory in our focus on the people at the center of such projects (Glazer and Peurach, 2015). In the study, the epistemic community were the people, teams, and units or university actors involved in developing, refining, and implementing the E-Corps model. Our investigation sought to reveal the relevant "theories, codes, and tools that govern interpretation, practice, and communication" used by university actors (Glazer and Peurach, 2015, p.181). Campbell and colleagues (2019) pointed to an example emergent epistemic community focused on pre-service science teacher education that formed around Ambitious Science Teaching (Windschitl et al., 2020). In this example, a theoretical stance (i.e., theory) supportive of early career science teaching anchored by instructional practices supported professionals in science teacher education to engage in codified language and performances supportive of science teaching (e.g., eliciting students initial ideas) and the development of tools (e.g., back-pocket questions) that have supported the collegial collaboration and work of those engaged in specialized ways (see also Stroupe et al., 2020). The present study extends such knowledge generated by existing scholarship by applying epistemic community theory to science education that takes place through service-learning.

\section{METHODS AND MATERIALS}

Research Setting: E-Corps Context. First made possible through internal incubator funding, E-Corps debuted in 2017 with a "soft launch", including the offering of a two-semester course "Climate Corps" that focused on the local impacts of climate change and responses to it. A year later, Brownfields Corps joined E-Corps. Stormwater Corps was added in 2020. Both the "hard launch" of the program and our inquiry took place during E-Corps' first externally-funded year (2019-2020).

E-Corps' courses consist of an initial semester on campus in the classroom and a second practicum semester in the field working with municipalities. The goal of the first semester is to understand the practical, social, and economic impacts of real-world local issues and how they can be addressed. During the first semester, students learn to work with online mapping tools (i.e., Arc GIS Online) that are often beyond the time and/or skill limitations of town staff. In the second semester, students' skills developed within classrooms are leveraged in internships when students are partnered with municipalities to design applications to community challenges to both provide real-world participatory learning experiences for students and community benefits. During both semesters, team assignments are designed to emphasize and support students' facility with social competencies, such as cooperation, teamwork, and communication.

E-Corps is housed at a large New England university classified by the Carnegie Commission on Higher Education as an R1, a doctoral university with very high research activity. A land and sea grant university, in fall 2020, it had nearly 33,000 total students enrolled in its five campuses. To date, although E-Corps courses have primarily targeted environmental majors, the courses have attracted students from 15 other majors, including other STEM majors (e.g., biological sciences, chemical engineering, civil engineering) and non-STEM majors (e.g., economics, English, political science, urban and community studies). Arnold and colleagues (2021) provide additional information on the students taking the courses and the courses themselves.

Participants and Data Collection Methods. Interviews with seven students and the seven faculty leading the three E-Corps courses, as well as participant observations of E-Corps team $(n=13)$ meetings were collected following protocols approved by the University of Connecticut Institutional Review Board. Informed consent was obtained from participants before the interviews and observations. Student and instructor interviewees came from each of the three E-Corps courses (see Table 1). All instructors were

Table 1. Data collection methods, participants, and recording method.

\begin{tabular}{|c|c|c|c|}
\hline $\begin{array}{l}\text { Data } \\
\text { Collection } \\
\text { Method }\end{array}$ & Number & $\begin{array}{l}\text { Type of Participants and } \\
\text { Timing of Data Collection }\end{array}$ & $\begin{array}{l}\text { Recording } \\
\text { Method }\end{array}$ \\
\hline \multirow{8}{*}{$\begin{array}{l}\text { Interviews } \\
\text { (11 total) }\end{array}$} & \multirow{5}{*}{7 students } & 1 Brownfields student: Fall 2019 & \multirow{5}{*}{$\begin{array}{l}\text { Audio, } \\
\text { followed by } \\
\text { transcription }\end{array}$} \\
\hline & & 2 Climate students: Fall 2019 & \\
\hline & & $\begin{array}{l}2 \text { Brownfields students: } \\
\text { Spring } 2020\end{array}$ & \\
\hline & & 1 Climate student: Spring 2020 & \\
\hline & & $\begin{array}{l}\text { 1 Stormwater student: } \\
\text { Spring } 2020\end{array}$ & \\
\hline & \multirow{3}{*}{7 instructors } & $\begin{array}{l}2 \text { Brownfields faculty (Penelope } \\
\text { and Phaedra): Fall 2019; } \\
\text { Spring 2020 }\end{array}$ & \multirow{3}{*}{$\begin{array}{l}\text { Audio, } \\
\text { followed by } \\
\text { transcription }\end{array}$} \\
\hline & & $\begin{array}{l}2 \text { Climate faculty (Elisabeth and } \\
\text { Scott): Fall 2019; Spring } 2020\end{array}$ & \\
\hline & & $\begin{array}{l}3 \text { Stormwater faculty (Wes, Dan, } \\
\text { and Paul): Spring } 2020\end{array}$ & \\
\hline \multirow{2}{*}{$\begin{array}{l}\text { Observations } \\
\quad(4 \text { total })\end{array}$} & \multirow[b]{2}{*}{4 meetings } & $\begin{array}{l}\text { Instructional and integration team } \\
\text { members: Fall } 2019 \text { (2 meetings) }\end{array}$ & \multirow{2}{*}{$\begin{array}{l}\text { Audio, } \\
\text { followed by } \\
\text { transcription }\end{array}$} \\
\hline & & $\begin{array}{l}\text { Instructional and integration team } \\
\text { members: Spring } 2020 \\
(2 \text { meetings) }\end{array}$ & \\
\hline
\end{tabular}


interviewed and completed two rounds of interviews, and seven students from the pool of approximately 70 were interviewed one time. Students were recruited to participate in interviews in one of two ways, their instructor either sent an email to the class asking if anyone was interested in participating, or instructors selected a small number of students to ask if they were interested. This latter recruitment method presents a limitation for this study given the potential effects of instructor selection for recruitment rather than opening it up to the entire class.

Interviews with 1-3 participants at a time were conducted by a researcher from the team who utilized "tell-me-more" follow-up questions and probes and requested examples, which encouraged interviewees to provide further details (Bernard, 2011). In order to collect data to inform our understanding of how E-Corps was implemented, a structured interview guide with special attention paid to items measuring the context of the implementation of the E-Corps model was used (see Appendix A and Appendix B for faculty and student interview guides respectively). Specifically, the items inquired about course experiences, practices, challenges, successes, projects, and feelings of support. For example, items that especially elicited how other members of the epistemic community supported faculty include:

- What, if anything, has been most important to this success?

- Can you think of how you may have used any of these strategies in your E-Corps course, as well as ways in which the experience may have supported or caused challenges for you?

- In what ways have you felt supported or do you feel supported for engaging students in the project?

In its broader focus on how instructors experienced the courses and worked together, the faculty interview protocol also elicited content related to the principles of DBIR and epistemic communities (i.e., how the instructors experienced the practice of the course, who supported them, what supportive collaborative refinement and improvement of the E-Corps model across courses).

One to three members of the research team participant observed each of the four E-Corps leader group meetings in which 13 institutional stakeholders, including the seven instructors, participated. The epistemic community under study includes this 13-person team, while the student interviews offer a point of triangulation. The E-Corps 13-person team consists of an instructional team focused on the development and refinement of instructional strategies that can be used across all three E-Corps courses and consists of the instructors of all three courses and a representative from the Center for Excellence in Teaching and Learning (CETL) on campus. Additionally an institutional, or integrational, team focused on identifying, fostering, and understanding the institutional changes needed to ensure the long-term success and viability of E-Corps as a new university public engagement model consists of faculty from the Office of the Provost and CETL, and also includes the directors of several of the university centers involved. The observation transcripts provided evidence relating to the processes through which the epistemic community interacted, as well as how they worked together to create and refine E-Corps iteratively based on their progress.

Additionally, all interviews and observations were audio recorded and transcribed verbatim. These data sources upon which we drew are listed in detail in Table 1. While not included here, additional studies are underway analyzing how local communities and their members are affected by and interact with E-Corps programming.

Analysis. The research team consists of a white man professor of education who is also one of the project's co-principal investigators, a white woman postdoctoral research associate trained as a cultural anthropologist, and an Asian man doctoral student in education. The research team is supported by the E-Corps grant and has the responsibility to examine the E-Corps programming from an education perspective to understand how it is working, to uncover how it might be improved, and to disseminate related findings to advance theory and practice.

Two members of the research team led the coding and analysis of the data while consulting with the third member to ensure codes and findings related to key concepts of the research question were representative of data. The initial task was for all three members of the research team to review each of the transcripts for familiarity. Next, the researchers used a three-step process wherein they first created a codebook based on themes discussed in research team meetings coming from members having read the transcripts. Second, the two research team members leading the coding established intercoder reliability. After creating the initial codebook, the two researchers each coded one interview independently to establish intercoder reliability (O'Connor and Joffe, 2020), and discussed all instances in which their applied codes differed to reach consensus and make additional codebook refinements (DeCuir-Gunby et al., 2011). Intercoder reliability was calculated using a comparison of line-by-line coding of the interview (Bernard, 2011), and the intercoder reliability was 83 percent when considering primary codes only. Given this, we decided to proceed with analysis, as 80 percent reliability is considered acceptable (Krippendorff, 2003; Landis and Koch, 1977). Third, one researcher then coded the remaining interviews and observation transcripts on paper, and another entered the codes into the qualitative data analysis program QSR NVivo 11.0. (Campbell et al., 2013).

We used thematic content analysis to analyze the cod- 
ed passages (Bazeley and Jackson, 2013; Braun and Clarke, 2006). First, we exported from NVivo all passages associated with each individual code. Then, we identified trends in relevant coded passages based on frequency or patterned nature of comments as well as their "keyness" or how well they related to the project's research question (Braun and Clarke, 2006, p. 82). To do this, the three researchers independently reviewed the exported excerpts and then met to discuss themes that emerged. The discussion was guided by the theoretical frames in this study, wherein the researchers considered the people and how they interacted with each other as an epistemic community as well as how these excerpts showed to what extent the principles of DBIR existed in the data. Based on this discussion, the group reached a consensus on the main points supported by the data. The trends were then grouped into themes presented in this article, and examples from excerpts were chosen to demonstrate points in the themes. Pseudonyms are used for all participants for anonymity.

\section{RESULTS}

Analysis showed that two main factors supported the implementation of E-Corps, both of which were intricately connected to the establishment of the epistemic community:

1. An existing university context including: funding, a longstanding epistemic community, and a resource-rich university environment;

2. A team orientation to both university-community partnership and aligned pedagogical practices.

Notably, features of DBIR were also found in these transcripts, showing that the epistemic community did DBIR as their community was formed and they worked toward their shared goals. The themes within these two factors are listed in Table 2.

Existing University Resources, People, and a Fertile Environment. The first main factor established the conditions within which an epistemic community could form. More specifically, the participants' perceived support connected to a context of resources, people, and university environment. Here, the implementation of E-Corps occurred within a larger existing context, including:

- Monetary resources from the National Science Foundation grant and incubator funds from the university;

- E-Corps instructors connected to communities and industry;

- E-Corps instructors coming together in a community committed to DBIR;

- A fertile university environment, including its CETL.

Journal of STEM Outreach
Table 2. Main factors and themes of findings.

\begin{tabular}{ll}
\hline \multicolumn{1}{c}{ Main Factors } & \multicolumn{1}{c}{ Themes } \\
\hline & $\begin{array}{l}\text { Monetary resources from the National } \\
\text { Science Foundation grant and incubator } \\
\text { funds from the university; }\end{array}$ \\
$\begin{array}{l}\text { 1. An existing university context } \\
\text { including funding, a longstanding } \\
\text { epistemic community, and }\end{array}$ & $\begin{array}{l}\text { E-Corps instructors connected to } \\
\text { communities and industry; }\end{array}$ \\
$\begin{array}{l}\text { a resource-rich university } \\
\text { environment. }\end{array}$ & $\begin{array}{l}\text { E-Corps instructors who came together } \\
\text { in an epistemic community committed to } \\
\text { DBIR; }\end{array}$ \\
& $\begin{array}{l}\text { A fertile university environment, including } \\
\text { its CETL. }\end{array}$ \\
\hline $\begin{array}{l}\text { 2. A team orientation to } \\
\text { university-community partnership } \\
\text { as well as aligned pedagogical } \\
\text { practices. }\end{array}$ & A robust university-community \\
partnership; \\
An instructor approach that was applied.
\end{tabular}

Funding was critical for the implementation of E-Corps because its courses required at least two instructors - this financial support of the instructional epistemic community members was needed to pay for participants' efforts in the shared work. For instance, when asked how she was supported in doing this work, Brownfields instructor Penelope noted, "If I was a professor and had to teach this [class] as part of my regular course load, forget it. It would be insane. If I don't have the funds to support somebody like [teaching assistant] Phaedra to do this, it's just impossible." When asked about how the E-Corps model might translate to other university contexts, Stormwater instructor Wes likewise mentioned that the course was not a job for one person:

\section{I don't think it's a one-person job, it's a two-per- son [job]. We have three [teaching Stormwater E-Corps]... I think the model of having two teachers with one taking the lead on the classroom semester, and one taking the lead on the practicum semester... is something that people really have to consider if they're going to tackle this.}

Several faculty members similarly commented that initial seed funding or incubator funds were necessary to support to costs associated with needing multiple instructors.

Instructors' connections to communities and industry were crucial in supporting student projects addressing community needs, and these resources enabled the developing epistemic community to be able to undertake its identified work. Several E-Corps faculty members were also Extension faculty whose occupations entail sustaining relationships with communities. When asked about extending the E-Corps model to other contexts, Dan, a Stormwater instructor, talked about the importance of involving such Extension faculty. He said the following, of which his two colleagues also teaching the class echoed in agreement: "The tie in with Extension. That piece will be challenging for professors who have no connection with the community. Having Extension partners, that's why this is easy for us." However, faculty did 
not necessarily need to be Extension faculty in title to have robust community relationships. When asked about how universities could implement the E-Corps model, Wes said the following of his colleagues:

I don't think you start this without first having a relationship with the town. Penelope...she's not from Extension but she spent [a lot of time]...talking to communities about various things having to do with brownfields.

Wes continued, noting that E-Corps faculty members had a lot of experience in working with communities on environmental issues:

\section{The three of us teaching Stormwater together have a combined 70 years of experience working with communities on stormwater management. Scott and Elisabeth had been working for five or six years with communities on climate issues.}

In addition, having faculty connected to industry partners was key given the real-world programming of E-Corps, again enabling the epistemic community to have the resources needed to undertake environmental service-learning, including instructors' abilities to secure local industry workers as guest speakers in class. This aspect of the courses was referenced throughout student interviews. As Brownfields student Ann said, "It was nice to hear from people who are actually out there working on the stuff we're learning about." Climate student Carol agreed:

I really liked...having other speakers come in...and being like, 'I am working on this right now and this is what's happening. This is the progress we've made.'If we need help, we've had [industry] people come in [and answer questions].

Similarly, when asked how she felt supported in her E-Corps course, Brownfield instructor Phaedra discussed the role played by professionals from various fields as they connected their expertise to student projects:

We've had helpful discussions with companies and professionals. Also having discussions with the community, regarding what they might need, what type of projects the students can do, and how we can make this happen... If we have questions, we can call [our industry partners and consultants] and they help us.

When asked specifically how it was that she had this circle of industry partners that was helping, Penelope said, "Well, I've worked in it. I had contacts from before because remediation is my field, and so I knew people over the years...
It's [also] a mix of relationships that came about because of E-Corps existing." Here, support from industry partners was made possible through existing faculty relationships that Penelope has cultivated over the decades that she has been a practicing engineer.

Reflections from participants in the faculty interviews and meeting transcripts suggest that earlier work during the incubator-funded period provided time for the faculty who started the program to build an epistemic community over the course of their sustained interactions around a shared goal, and this community was crucial to the launch of the program. In that three-year incubator period, the team collaborated in a community to create the E-Corps framework of how to run and design the classes. The first year was spent planning, and teaching the courses began in the second year. This background and conversations stemming from it were indicative that community members were practicing iterative, collaborative course design central in epistemic communities that also is found in DBIR. For instance, when asked in what ways they were supported in E-Corps, Scott emphasized that his colleagues helped each other by providing consultation and advice in executing projects across disciplines. He agreed that there was a community of E-Corps instructors and administrators, and Elisabeth indicated she felt the same way. Scott commented:

We support each other, Elisabeth and I do, Wes and others help us by taking over students that deal with low impact development and MS4 [stormwater regulatory program] projects because they're more versed in that... We all share ideas...we all support each other.

This interest in learning from other instructors and individuals and feeling like part of a team was common across the E-Corps team.

E-Corps' progress is also attributable to the broader university context during the program's implementation that supported participation from a range of epistemic community members outside of instruction, including, for instance, a member of CETL - this allowed persistent problems of practice to be examined from multiple stakeholders' perspectives (the first tenet of DBIR). During E-Corps team meetings, attendees shared knowledge and discussed the successes and challenges they faced in their classroomsepistemic community members took up this knowledge and used it in their own efforts as well as provided feedback to help others, again, a commitment to iterative and collaborative design (the second tenet of DBIR). Dorothy, the CETL Director of Faculty Development, attended E-Corps team meetings. During a team meeting, Penelope talked about developing students' technical writing skills on their project write-ups - one of the areas that was challenging for her. 
Dorothy responded:

CETL is available to help think about these ways that you may structure your class or the activities you would include, including that reasoning... When you're talking about the technical writing skills that are needed to be further developed, that's a place where we can help.

In the meeting, project Co-PI and education research leader Trevor connected Dorothy's comments to group's goals:

[Next year,] maybe we bring Dorothy in and perhaps have her help us think about what is it about role plays that's so essential, and how can we make those experiences even better or how can we work together to make it better.

In another example, CETL had helped Elisabeth and Scott develop the popular Climate Corp role playing exercise used in class that later was implemented by other instructors as well. Elisabeth noted, "The role playing exercise, when we had more students the second year, we went over to CETL and got some fabulous advice on how to restructure it, add to it, so we could do it with more students." Scott agreed, "As it turned out, we got great suggestions from them."

Together, these comments show how conditions at this New England university contributed to establishing E-Corps' epistemic community. They further illuminate how the community saw E-Corps as a program with a shared goal where learning from others was encouraged and with DBIR efforts that were iterative and constantly improving.

\section{A Strong University-Community Partnership and Shared} Orientation to Applied Teaching. The second main factor included a shared team orientation to the university-community partnership and aligned pedagogical practices. This shared orientation was central to the establishment of an epistemic community since it supported a condition of coordination, alignment, and collaborative work of people, teams, and units to achieve a goal (i.e., the institutionalization and development and refinement of E-Corps courses). The shared orientation specifically includes commitment to:

- A robust university-community partnership;

- An instructor approach that was applied.

A shared orientation to the robust university-community partnership was indicated in data as instructors reported prioritizing community needs in their courses and student community projects - this focus on community underscored a common language or code in which the groups' efforts were understood. For example, when discussing spreading the E-Corps model to other universities in interview, Elisabeth shared, "We're talking applied science and that focus has to be on the community partners and what they need." Wes also discussed the importance of prioritizing local community needs and appreciating specific community contexts. In interview, when asked about spreading the E-Corps model to other campuses, he said:

Grounding it in that local issue that applies to the community and expanding it beyond to understand how it impacts that state and the different actors and people [is important]. [Local] green stormwater infrastructure is significantly different [compared to] how it's going to be applied [elsewhere in the state] ... Thinking about it from a community angle gives you the tools to think about it in your own community.

Similarly, a primary way that the Brownfields course supported communities was by having students write Environmental Protection Agency (EPA) grants that towns could use to apply for funding to address their issues. As Brownfields student Ann noted, "Our one big assignment all semester was to write a grant to try to get a town money to clean up brownfield sites." Since the inception of the course, out of 19 student teams, 12 EPA grants (e.g., site assessment and community cleanup grants) have been submitted, and four of those were awarded to local municipalities as a result of these collaborations.

Data showed that instructor teaching practices were generally triangulated with the focus on communities. Instructors and students reported warm reception from communities and felt that their work was valued. For instance, when asked in interview how he felt supported in doing service-learning projects with his students, Scott talked about how appreciative the communities were with the work that was being done:

The communities are really interested in having something done... The one [student that studied] the impacts of sea level rise on brownfields in three different communities... This community would have easily paid \$30-40,000 for such a report... The communities support us because they want these things to happen.

Brownfields student Kadina recalled that the communities she worked with respected and valued her project. She said in interview:

The towns I've worked with have been really encouraging and appreciative of what we're doing. Last semester they really didn't know what they were doing. They were happy and thankful that we were creating this for them. 
Accordingly, to support the university-community partnership, instructors facilitated students' connections with the towns. Instructors recognized that spending time in the communities was necessary in order to design appropriate interventions and applications, so they often accompanied their students on site visits. Likewise, of the university-community relationships, at an E-Corps team meeting Trevor said, "We think about these as long-term collaborations. We think about us coming back to these communities, multiple years staying with those communities." Trevor's summary of the relationship between the towns and university, and the other comments here, illustrates how the epistemic community made sense of and thought about their sustained community approach.

Just as shared codes were used by participants showing how they thought about and discussed the community orientation of the work, faculty and student data illustrated that instructor practices generally formed a cohesive orientation connected to community needs. Faculty iteratively talked about the importance of not just teaching students academic components, but also making connections to the real world. For instance, Scott shared how important it was that students gain skills, including technical writing ability, that would facilitate their future work. He said: "One of the things that universities [interested in doing E-Corps] will have to let go of is the strict academic rigors... We want them to get more into their own observations." This also provides evidence of DBIR tenet four, focused on developing capacity for sustaining change- Scott and others discussed how STEM and universities must change to support applied teaching and environmental improvements. More specifically, at the meeting when Penelope and Dorothy had discussed how CETL could help improve students' writing in the E-Corps team meeting, Scott had commented that he was open to such efforts, sharing:

\section{I think that's a great idea. Writing...like a consultant would. I just made a note to myself that we could have as one of the assignments... an exercise on writ- ing like a consultant. We give them a scenario and ask them to create a report.}

Accordingly, students and faculty reported that courses were grounded in applications addressing real-world issues. For instance, Carol noted how class activities connected to issues towns were facing: "I really like the planning part of it and coming up with solutions. Like this project we're doing where, [due to sea level rise,] you're having to move people out of Miami and find homes for them." Brownfields student Jeanna similarly connected hands-on, real-world experiences towns were facing to career options:

I'm [majoring in] Environmental Engineering... We could go into brownfields as a career choice once Journal of STEM Outreach we got our degrees. It was a really good, firsthand experience of doing something that you can actually do career-wise in the future.

Brownfields student Sandra, who majors in Environmental Health and Science, concurred: "It's getting to do work hands-on. Working with the town was really informative and there's something that we can actually do after college." Further, students discussed being able to understand environmental issues from multiple sides. Climate student Lewis talked about the course providing insight as to how local laws are created and implemented with regards to the environment:

It gave me knowledge on things I didn't think about, like how important municipal governments are... I think that'll be something that's a front when it comes to addressing climate change...the real-world applications are priceless.

Climate student Nisha agreed that being able to work with municipalities helped her understand the relationship between law implementation and environmental outcomes from multiple angles: "I learned about the policy side to everything environmental. I got to learn some of the law involved. We got to meet people that were in place making these laws."

In the end, students often talked about how they felt supported by E-Corps professors. Students talked about instructors doing site visits with them, having open door policies, and supporting them holistically. Stormwater student Tim noted:

They were helpful in guiding me, not telling me, "You should be doing this." [I told them], "I was going to quantify remediation costs for sites." They said, "You may run into trouble because of differences in testing"-factors I didn't consider. [They redirected me,] "If you can't quantify it, talk about how it's going to impact systems you understand."

These excerpts illustrate how faculty approached teaching in an applied sense across courses where iterative collaboration around instructional approaches is one anchor around which epistemic communities can be coordinated.

\section{DISCUSSION}

Participants' comments suggest that a context of resources and university environment as well as shared faculty orientation to university-community partnership with applied teaching practices was crucial to the implementation of E-Corps and the emergence of an epistemic community. Specific to E-Corps, due to the intensive nature of the 
courses and the expertise they required, each course was taught by two instructors, thus these classes ran at a higher cost to the university than courses led by one instructor. At the same time, they had to be of a small size since they were hands-on. As noted, incubator and later external funding made the multiple-instructor model feasible. Then, the establishment of the core interdisciplinary team was key to E-Corps' launching. This team included professors teaching the courses who had the necessary sustained interactions with communities and existing relationships in industry to recruit speakers and consultants. These resources were magnified in the university environment supported by CETL. The implementation of E-Corps was aided by instructors prioritizing community needs. According to participants, sustained community involvement central to service-learning was facilitated by pedagogical approaches, decisions, and practices of faculty. Students talked about feeling supported by instructors, and how instructors made the class hands-on and based upon real world environmental issues. These pedagogical practices were nurtured by CETL and disseminated and collaboratively and iteratively taken up by others in the team meetings.

Bringle and Hatcher's (2000) findings on the aspects needed for institutionalization of service-learning translate well to the work here. These three aspects include deliberate institutional planning (seen at the research site in the university's broader environmental turn, initial incubator and other support by the university provost office), the development of campus infrastructure (the aforementioned context of resources, people, and university environment), and having a centralized office (E-Corps is located in Extension and run by the core interdisciplinary team). This shows that though environmental sustainability focused service-learning has unique needs, it benefits from the same resources needed in more general service-learning programs.

As illustrated above, E-Corps team members came together as an epistemic community with a shared focus on working together and a shared orientation to how E-Corps was run. The shared focus on working together was seen, among other ways, in how instructors across courses "all share ideas...we all support each other." The shared orientation was evidenced in common language and efforts in centering the courses and teaching practices around applied activities benefitting communities. As Glazer and Peurach (2015) explain, the work of epistemic communities entails the pursuit of common goals and ways of thinking and talking about pursuits that are fostered by shared practices. As members contributed to the sustained dialogue focused on the shared language, practices, and pursuits related to working together and running the program, they embodied the characteristics of epistemic communities and adopted shared codes and orientations. Importantly, the quarterly team meetings facilitated the team's practice as an epistemic community, allowing members to exchange ideas. The resources available in the university were multiplied as they were taken up by instructors and disseminated in the meetings. A shared orientation to active learning from others and orientation to articulating and improving how the model operates was demonstrated.

Furthermore, there was a shared commitment to DBIR (Fishman et al., 2013). Firstly, E-Corps team members spread across the university system at multiple levels (e.g., university leadership, instructors) often talked in meetings and interviews about community needs, which relates to the first DBIR tenet focused on persistent problems of practice from multiple stakeholders' perspectives (Fishman et al., 2013). The second DBIR tenet, a commitment to iterative and collaborative design, is seen, for instance, when Trevor discussed the group iteratively improving the role playing activity together. He suggested bringing Dorothy in and discussing why their practices are essential and how the team could work together to make them better. The third DBIR tenet concerned with developing theory and knowledge related to both classroom learning and implementation through systematic inquiry is evidenced by the present study as a whole and the efforts of E-Corps leadership participants in participating in this research as we extend work on epistemic communities and DBIR through our look at E-Corps. Finally, the last DBIR tenet regarding a concern with developing capacity for sustaining change is seen in such instructor comments as those when faculty talked about what universities would need to do to implement and sustain such a program, including making pedagogical adjustments.

This study is the first research dissemination effort in the group's systematic approach of E-Corps. The study contributes to the existing scholarship on epistemic communities and DBIR by offering insight into the conditions supporting the formation of epistemic communities and they role they can play in environmentally-related service-learning program implementation, as well as by illustrating what DBIR looks like in situ. By examining how resources, including people, and contextual factors supported the implementation of E-Corps, the study expands the current knowledge about the implementation of environmentally focused service-learning. Further, our use of qualitative methodologies complements the quantitative findings of previous research (e.g., Bringle and Hatcher, 2000), offering robust, complementary evidence to paint a picture of how service-learning may be institutionalized, offering the reader and stakeholders concrete examples that could be useful in the expansion of such programming.

\section{CONCLUSION}

Together, the commitment of the E-Corps epistemic community to DBIR and the shared focus of the E-Corps 
epistemic community on the promotion of the STEM-related skills in the New England communities appeared central in the implementation of the environmental sustainability-focused service-learning programming. Resources such as those identified in this study will likely be crucial in the implementation of similar environmental-sustainability focused service-learning models across university contexts. Feasibility of implementation must be balanced with available resources and contexts. Smaller universities with fewer faculty and funding may struggle in committing two instructors to classes. This could be addressed through adjustments in class sizes, engagements with fewer communities, or through condensing activities to a shorter duration than a semester, such as done through something like a two-day conservation workshop described in Cisneros et al. (2021) and Chadwick et al. (2018). Also, colleges with fewer numbers of experienced STEM faculty could benefit by bridging more diverse fields. Specifically, E-Corps involved only STEM faculty, whereas social scientists practicing sociology of environmental racism or applied anthropology of water resources could provide the expertise and support needed in other contexts (i.e., Alexander et al., 2021; Lehigh et al., 2020). At the same time, larger universities could scale up the model by harnessing relationships between university campuses to expand efforts to more difficult to reach communities that are often underserved.

Future work should contrast diverse university contexts to see how such program launches work in varying areas. This is important to offer a more comprehensive model of how such engaged programs may be implemented across university contexts. This is a crucial line of inquiry given that universities have much potential to address environmental concerns faced by communities, and that they can play a crucial role in training the next general of environmental scientists.

\section{ASSOCIATED CONTENT}

Supplemental material mentioned in this manuscript can be found uploaded to the same webpage as this the manuscript.

\section{AUTHOR INFORMATION Corresponding Author}

Rebecca Campbell-Montalvo. Department of Curriculum and Instruction, University of Connecticut. rebecca.campbell@uconn.edu

\section{Author Contributions}

The manuscript was written through contributions of all authors. All authors have given approval to the final version of the manuscript.
This work is licensed under a Creative Commons Attribution 4.0 International (CC BY 4.0) License.

\section{ACKNOWLEDGMENTS}

The authors would also like to gratefully acknowledge the contributions of the many members of the E-Corps instructional, research, evaluation, and integration teams.

\section{FUNDING SOURCES}

The Environment Corps project is supported by a grant from the National Science Foundation Improving Undergraduate STEM Education: Education and Human Resource (IUSE: EHR) program, Award Number 1915100. Several private sector and foundation funders have also provided support to early efforts that contributed to the formation of the E-Corps.

\section{ABBREVIATIONS}

CETL: Center for Excellence in Teaching and Learning; DBIR: Design Based Implementation Research; E-Corps: Environment Corps; EPA: Environmental Protection Agency; IUSE: EHR: Improving Undergraduate STEM Education: Education and Human Resource

\section{REFERENCES}

Alexander, W. L., Wells, E. C., Lincoln, M., Davis, B. Y., and Little, P. C. (2021). Environmental justice ethnography in the classroom: Teaching activism, inspiring involvement. Human Organization, 80(1), 37-48.

Arnold, C., Barrett, J., Campbell, T., Chrysochoou, M., and Bompoti, N. (2021). The Environment Corps: Combining classroom Instruction, service-learning and extension outreach to create a new model of community engaged scholarship at the University of Connecticut. Journal of Higher Education Outreach and Engagement, 25(2), 215-232.

Bazeley, P., and Jackson, K. (Eds.). (2013). Qualitative data analysis with NVivo. Sage Publications Inc. https://doi. org/10.1111/j.1365-2850.2008.01257.x

Begun, A. L., Berger, L. K., Berger, Otto-Salaj, L. L., and Rose, S., J. (2010). Developing effective social work university-community research collaborations. Social Work, 55(1), 55-62.

Bernard, H. R. (2011) Research methods in anthropology: Qualitative and quantitative approaches $\square$ (5th Ed.). AltaMira Press.

Braun, V., and Clarke, V. (2006). Using thematic analysis in psychology. Qualitative Research in Psychology, 3(2), 77101. https://doi.org/10.1191/1478088706qp063oa 
Bringle, R. G., and Hatcher, J. A. (1995). A service-learning curriculum for faculty. Michigan Journal of Community Service Learning, 2, 112-122.

Bringle, R. G., and Hatcher, J. A. (2000). Institutionalization of service learning in higher education. The Journal of Higher Education, 71(3), 273-290.

Campbell, J. L., Quincy, C., Osserman, J., and Pedersen, O. K. (2013). Coding in-depth semistructured interviews: Problems of unitization and intercoder reliability and agreement. Sociological Methods and Research, 42(3), 294320. https://doi.org/10.1177/0049124113500475

Campbell, T., Verma, G., Melville, W., and Park, B. (2019). JSTE as a forum for engaging in knowledge generation and discourses in science teacher education, equity and justice-focused science teacher education, and professional learning for science teacher education scholars. Journal of Science Teacher Education, 30(5), 429-433.

Chadwick, C., Dickson, D., Arnold, C., Cisneros, L. Volin, C., Campbell, T., Moss, D. M., and Rodriguez, L. (2018, September). Connecting generations through informal geospatial and conservation education. Journal of Extension. $56(5), 1-3$.

Cisneros, L. M., Simmons, J., Campbell, T., Freidendelds, N., Arnold, C., Chadwick, C., Dickson, D., Moss, D., Rodriguez, L., and Volin, J. (2021). Program principles to support teen-adult community conservation efforts. Frontiers in Education - STEM Education Section. https://doi. org/10.3389/feduc.2021.674667

DeCuir-Gunby, J. T., Marshall, P. L., and McCulloch, A. W. (2011). Developing and using a codebook for the analysis of interview data: An example from a professional development research project. Field Methods, 23(2), 136-155. https:// doi.org/10.1177/1525822X10388468

Dienhart, C., Maruyama, G., Snyder, M., Furco, A., McKay, M. S., Hirt, L., and Huesman, R. (2016). The impacts of mandatory service on students in service-learning classes. The Journal of Social Psychology, 156(3), 305-309. https://doi. org/10.1080/00224545.2015.1111856

Eflin, J. E., and Sheaffer, A. L. (2006). Service-learning in watershed-based initiatives: Keys to education for sustainability in geography? Journal of Geography, 105(1), 33-44. https://doi.org/10.1080/00221340608978656

England, Y. A., and Marcinkowski, T. (2007). Environmental service-learning programs in Florida high schools and colleges: Nature, status, and effects as determined by a statewide program census. The Journal of Environmental Education, 38(4), 51-60. https://doi.org/10.3200/ JOEE.38.4.51-60

Fishman, B. J., Penuel, W. R., Allen, A. R., Cheng, B. H., and Sabelli, N. (2013). Design-based implementation research: An emerging model for transforming the relationship of research and practice. National Society for the Study of Education, 112(2), 136-156.
Geller, J. D., Zuckerman, N., and Seidel, A. (2016). Service-learning as a catalyst for community development: How do community partners benefit from service-learning? Education and Urban Society, 48(2), 151-175. https://doi. org/10.1177/0013124513514773

Glazer, J. L., and Peurach, D. J. (2015). Occupational control in education: The logic and leverage of epistemic communities. Harvard Educational Review, 85(2), 172-202. https:// doi.org/10.17763/0017-8055.85.2.172

Helicke, N. A. (2014). Learning and promoting urban sustainability: Environmental service learning in an undergraduate environmental studies curriculum. Journal of Environmental Studies and Sciences, 4(4), 294-300. https://doi. org/10.1007/s13412-014-0194-8

Hughes, C. S., and Estes, C. A. (2005). The influence of environmental education on environmentally responsible behaviors of undergraduate students in a traditional and nontraditional setting. Journal of Experiential Education, 27(3), 308-310.

Hyde, B., and Barrett, J. (2017). Municipal issues and needs for addressing climate adaptation in Connecticut. Report of the University of Connecticut Center for Land Use Education and Research and the Connecticut Sea Grant College Program. https://clear.uconn.edu/publications/climate/Report_Municipal_Needs_Assessment_Sept_2017.pdf

Krippendorff, K. (2003). Content analysis: A guide to its methodology. Sage Publications Inc.

Landis, J. R., and Koch, G. G. (1977). The measurement of observer agreement for categorical data. Biometrics, 33(1), $159-174$.

Lehigh, G. R., Wells, E. C., and Diaz, D. (2020). Evidence-informed strategies for promoting equitability in brownfields redevelopment. Journal of Environmental Management, 261, 110150 .

Maurana, C. A., and Goldberg, K. (1996). A successful academic-community partnership to improve the public's health. Academic Medicine, 71(5), 425-431.

Meyer, C. L., Harned, M., Schaad, A., Sunder, K., Palmer, J., and Tinch, C. (2016). Inmate education as a service learning opportunity for students: Preparation, benefits, and lessons learned. Teaching of Psychology, 43(2), 120-125. https:// doi.org/10.1177/0098628316636278

O'Connor, C., and Joffe, H. (2020). Intercoder reliability in qualitative research: Debates and practical guidelines. International Journal of Qualitative Methods, 19, 1-13. https:// doi.org/10.1177/1609406919899220

Olberding, J. C., and Hacker, W. (2016). Does the "service" in service-learning go beyond the academic session. Assessing longer term impacts of nonprofit classes on community partners. Journal of Nonprofit Education and Leadership, 6(1), 25-46. https://doi.org/10.18666/JNEL2016-V6-I1-7201 
Penuel, W. R., Fishman, B. J., Haugan Cheng, B., and Sabelli, N. (2011). Organizing research and development at the intersection of learning, implementation, and design. Educational Researcher, 40(7), 331-337. https://doi. org/10.3102/0013189X11421826

Salam, M., Iskandar, D. N. A., Ibrahim, D. H. A., and Farooq, M. S. (2019). Service learning in higher education: A systematic literature review. Asia Pacific Education Review, 20(4), 573-593. https://doi.org/10.1007/s12564-019-09580-6

Stroupe, D., Hammerness, K., and McDonald, S. (2020). Preparing Science Teachers through Practice-Based Teacher Education. Boston, MA: Harvard Press.

Volchok, E. (2017). Service-learning: In service of whom? A professor of business reflects on resolving an underlying tension in service-learning. Cogent Education, 4(1). https://www.cogentoa.com/article/10.1080/233118 6X.2017.1299075.pdf

Windschitl, M., Braaten, M., and Thompson, J. (2020). Ambitious Science Teaching. United States: Harvard Education Press.

Yoshino, A. (2005). Environmental outcomes of wilderness-based programs of different lengths. Journal of Experiential Education, 27(3), 314-317. 